$02.4 ; 13.2$

\title{
Термодесорбционный спектрометр труднолетучих активных органических соединений
}

\author{
(C) С.С. Исхакова, У. Хасанов, У.Х. Расулев, Д.Т. Усманов \\ Институт ионно-плазменных и лазерных технологий им. У.А. Арифова АН Узбекистана, Ташкент, Узбекистан \\ ฯ E-mail: usmanov@iplt.uz
}

Поступило в Редакцию 8 июля 2020г.

В окончательной редакции 12 сентября 2020г

Принято к публикации 14 сентября 2020 г.

\begin{abstract}
Представлены результаты развития нового типа газоаналитического прибора для обнаружения труднолетучих активных органических соединений: наркотиков, психотропных препаратов и их метаболитов, загрязнителей окружающей среды. Он основан на принципе термодесорбции в сочетании с поверхностной ионизацией молекул исследуемого аналита. В исследованиях по обнаружению следовых количеств (oт $0.1 \mathrm{ng})$ в экстрактах проб идентификация аналита осуществляется путем сравнения термодесорбционных спектров, а определение их количества - по калибровочным кривым эталонных образцов, имеющихся в электронной базе спектрометра.
\end{abstract}

Ключевые слова: термодесорбция, поверхностная ионизация, газоанализатор, наркотики, психотропные препараты, загрязнители.

DOI: 10.21883/PJTF.2020.24.50423.18458

Развитие новых методов и разработка на их основе различных экологически чистых относительно простых и недорогих, но селективных и высокочувствительных портативных приборов экспрессного внелабораторного химического анализа труднолетучих активных органических соединений (АОС), несмотря на достигнутые успехи [1], остаются актуальной проблемой аналитической химии [2,3]. Одним из возможных путей, позволяющих решить эту проблему, может быть развитие новых типов газоаналитических приборов, основанных на явлении термоионной эмиссии - поверхностной ионизации (ПИ) органических молекул [4-11]. Ее важной особенностью является возможность реализации метода в атмосфере воздуха [4].

Целью настоящей работы является дальнейшее развитие поверхностно-ионизационного газоаналитического приборостроения, а также разработка действующего в условиях атмосферы воздуха относительно простого экспрессного высокочувствительного анализатора для обнаружения следовых количеств АОС в различных пробах и получения данных о их термодесорбционных (ТД) поверхностно-ионизационных характеристиках.

Суть предложенного метода заключается в сочетании термодесорбции труднолетучих молекул АОС с их последующей ионизацией путем ПИ на поверхности термоэмиттера (рис. 1,a). Спектрометр состоит из температурно-программируемого испарителя молекул аналита и поверхностно-ионизационного детектора (ПИД). При пропускании через детектор анализируемой смеси поступающие с потоком воздуха на поверхность термоэмиттера молекулы аналита и продукты их фрагментации могут десорбироваться в виде ионов. Для ускорения и обеспечения условий попадания положительных ионов на коллектор между электродами детектора прикладывается постоянное напряжение. Через прибор прокачивается воздух в направлении от испарителя к коллектору.

Микроколичества анализируемого образца (обычно $1-2 \mu 1$ раствора) наносятся на поверхность испарителя, который нагревается электрическим током в температурном диапазоне с определенной скоростью $T(t)$. При этом одновременно с зависимостью температуры испарителя от времени $T(t)$ записывается зависимость ионного тока $I(t)$ (рис. $1, b)$. Спектр отражает динамику температур испарения (сублимации) $T_{\max }^{s}$ и десорбции $T_{\max }^{d}$ молекул аналита с поверхности испарителя. Полный ионный ток определяется площадью под спектром в кулонах, и его расчет осуществляется автоматической программой ПК. Идентификация исследуемого аналита проводится по температурам сублимации $T_{\max }^{s}$ и десорбции $T_{\max }^{d}$ посредством сравнения с электронной базой данных ТД-спектров АОС, количество определяется путем сравнения площади под спектром $I(t)$ с калибровочными кривыми.

В отличие от традиционных установок для термодесорбционных исследований [12] в разработанном приборе измерения проводятся в условиях атмосферы воздуха. Разработанный ТД-спектрометр существенно отличается от предыдущей версии $[10,11]$. С целью увеличения коэффициента использования вещества и разрешения спектрометра изменены геометрия и размеры ПИД, модернизирован испаритель и оптимизировано расстояние испаритель-термоэмиттер. При этом температурная развертка испарителя изменена на прямолинейную и изотермическую. Для улучшения характеристики потока используется круглая форма тракта движения газовоздушной смеси от испарителя к термоэмиттеру. Спектрометр связан с персональным компьютером, 

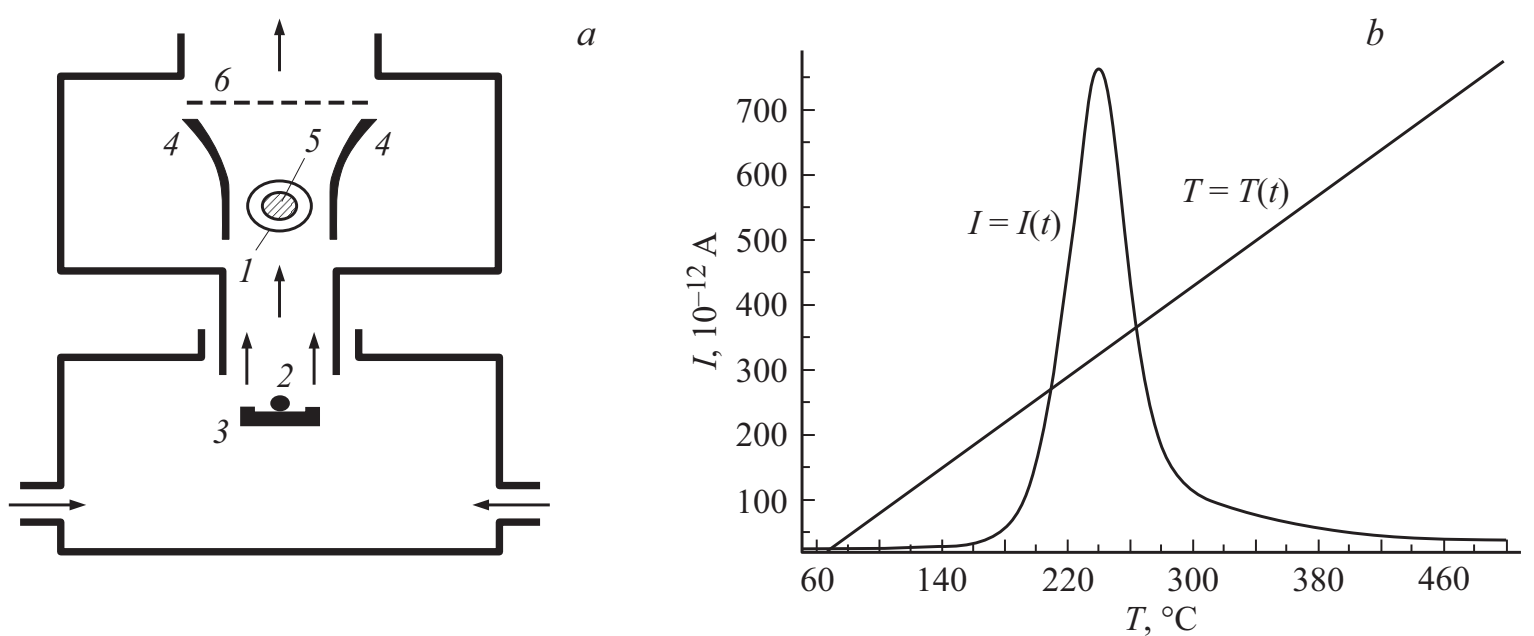

Рис. 1. $a-$ схема и принцип действия термодесорбционного поверхностно-ионизационного спектрометра: $1-$ эмиттер, $2-$ анализируемый образец, 3 - испаритель, $4-$ фокусирующие электроды, 5 - нагреватель, $6-$ коллектор ионов; $b-$ зависимости $I=I(t)$ и $T=T(t)$.

запись и обработка спектров осуществляются с помощью разработанной специальной программы. Идентификация спектра исследуемого аналита проводится путем сравнения со спектрами АОС, имеющимися в электронном банке спектров, а определение его количества - по калибровочным кривым. В качестве термоэмиттера ПИД $[5,13,14]$ использован окисленный монокристаллический молибден, легированный иридием $(\sim 1-2 v o l . \%)$ [15]. Испаритель представляет собой графитизированную металлическую чашку с диаметром $3 \mathrm{~mm}$ и высотой $1.5 \mathrm{~mm}$. На испаритель наносятся микроколичества раствора аналита с помощью шприца „Agilent“ объемом $5 \mu$ l. Растворы готовились путем последовательного разбавления анализируемых веществ. В качестве растворителей использовались ацетонитрил и этиловый спирт. Для калибровки прибора как по току (ионизационная эффективность), так и по $T_{\max }^{s}$ (линейность диапазона развертки) использованы эталонные хроматографически чистые образцы амитриптилина с $T_{\max }^{s}=110^{\circ} \mathrm{C}$ и морфина с $T_{\max }^{s}=180^{\circ} \mathrm{C}$ при количестве вещества $50 \mathrm{ng}$.

На рис. 2 представлены типичные зависимости $I(T)-$ ТД-спектры некоторых препаратов. Видно, что каждое вещество имеет характерную температуру максимума $T_{\max }^{s}$.

Среди них наиболее высокую температуру имеет AB-CHMINACA $\left(200^{\circ} \mathrm{C}\right)$, а наиболее низкую $\Delta^{9}$-тетрагидроканнабинол $\left(134^{\circ} \mathrm{C}\right)$, диазепам занимает промежуточное положение $\left(160^{\circ} \mathrm{C}\right)$. Эталонные образцы ( $\Delta^{9}$-тетрагидроканнабинол и AB-CHMINACA) имеют узкие пики $T_{\max }^{s}$. В спектре коммерческого образца диазепама расширение „хвоста“ спектра объясняется присутствием в препарате примесей, подтвержденным газохроматографическим/масс-спектрометрическим анализом. В ТД-спектре первым (основным) пиком является сублимационный $T_{\max }^{s}$. Появление второго (вы-

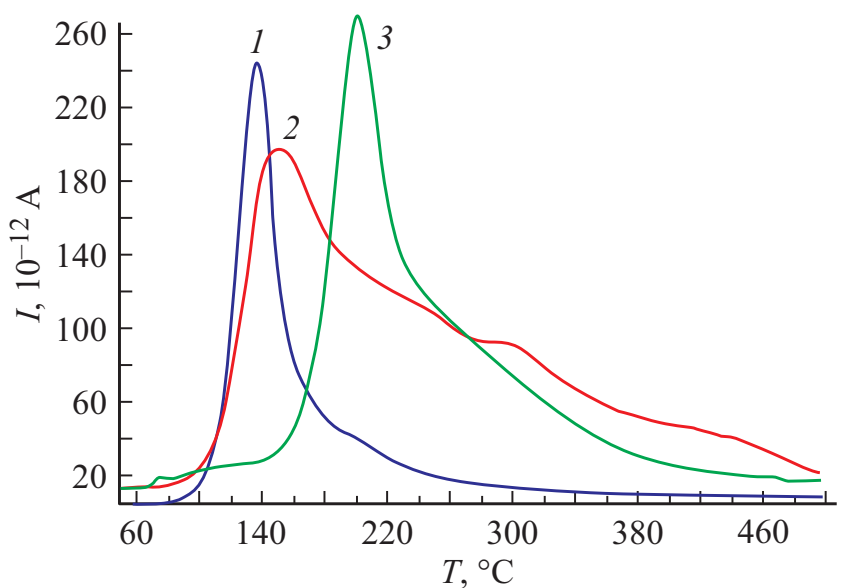

Рис. 2. ТД-спектры различных образцов. 1 - тетрагидроканнабинол (200 ng), 2 - диазепам (50 ng), 3 - AB-CHMINACA (50 ng).

сокотемпературного) пика $T_{\max }^{d}$ в спектре связано с десорбцией адсорбированных молекул аналита с поверхности испарителя. Величина тока, соответствующего $T_{\max }^{d}$, ограничена, так как она определяется количеством адсорбционных центров, имеющихся на поверхности испарителя. Десорбционный пик появляется только для тех соединений, в которых ионизационная эффективность высока (от $100 \mathrm{C} / \mathrm{mol})$ и которые при десорбции дают токи от $10^{-11} \mathrm{~A}$. Для регистрации десорбционных пиков соединений, имеющих относительно низкие ионизации (менее $100 \mathrm{C} / \mathrm{mol}$ ), необходимо работать в режиме над уровнем шума $\left(10^{-14}-10^{-13} \mathrm{~A}\right)$, вводя компенсацию фонового тока.

На рис. 3 приведен ТД-спектр смеси амитриптилина и морфина. Как видно, пики $T_{\max }^{s}$ компонентов смеси хорошо разрешаются благодаря большой разности тем- 
Термодесорбционные и поверхностно-ионизационные характеристики АОС

\begin{tabular}{|c|c|c|c|c|c|c|c|}
\hline Вещество & Состав & $\begin{array}{c}M, \\
\mathrm{~g} / \mathrm{mol}\end{array}$ & $T_{m},{ }^{\circ} \mathrm{C}$ & $\begin{array}{c}T_{\max }^{s}, \\
{ }^{\circ} \mathrm{C} \\
(\text { при } \\
m=50 \\
\text { ng) }\end{array}$ & $\begin{array}{c}\text { Иониза- } \\
\text { ционная } \\
\text { эффек- } \\
\text { тивность, } \\
\text { C/mol }\end{array}$ & $\begin{array}{c}\text { Преде- } \\
\text { лы } \\
\text { обнару- } \\
\text { жения, } \\
\text { pmol }\end{array}$ & $\begin{array}{c}\text { Линей- } \\
\text { ный } \\
\text { динами- } \\
\text { ческий } \\
\text { диапазон }\end{array}$ \\
\hline \multicolumn{8}{|c|}{ Наркотические вещества } \\
\hline Морфин & $\mathrm{C}_{17} \mathrm{H}_{19} \mathrm{NO}_{3}$ & 285 & $254[16]$ & 180 & 42 & 1.1 & 3.0 \\
\hline Героин & $\mathrm{C}_{21} \mathrm{H}_{23} \mathrm{NO}_{5}$ & 369 & $171[16]$ & 150 & 74 & 0.37 & 3.0 \\
\hline Кокаин & $\mathrm{C}_{17} \mathrm{H}_{24} \mathrm{NO}_{4}$ & 303 & $98[16]$ & 132 & 220 & 0.1 & 4.2 \\
\hline Амфетамин & $\mathrm{C}_{9} \mathrm{H}_{13} \mathrm{~N}$ & 135 & $232^{*}[17]$ & 170 & 32 & 5.2 & 2.5 \\
\hline Метамфетамин & $\mathrm{C}_{10} \mathrm{H}_{15} \mathrm{~N}$ & 149 & $212^{*}[17]$ & 135 & 98 & 2.6 & 3.0 \\
\hline$\Delta^{9}$-тетрагидроканнабинол & $\mathrm{C}_{21} \mathrm{H}_{30} \mathrm{O}_{2}$ & 314 & $200^{*}[17]$ & 134 & 9.2 & 1.8 & 2.1 \\
\hline AB-CHMINACA (Спайс) & $\mathrm{C}_{20} \mathrm{H}_{28} \mathrm{~N}_{4} \mathrm{O}_{2}$ & 356 & $332[18]$ & 200 & 78 & 1.5 & 2.7 \\
\hline \multicolumn{8}{|c|}{ Психотропные препараты } \\
\hline Диазепам & $\mathrm{C}_{16} \mathrm{H}_{13} \mathrm{ClN}_{2} \mathrm{O}$ & 284 & $132[18]$ & 160 & 58 & 3.4 & 3.0 \\
\hline Амитриптилин & $\mathrm{C}_{20} \mathrm{H}_{23} \mathrm{~N}$ & 277 & $188[17]$ & 110 & 900 & 0.15 & 4.5 \\
\hline Хлорпромазин & $\mathrm{C}_{17} \mathrm{H}_{19} \mathrm{ClN}_{2} \mathrm{~S}$ & 318 & $57[18]$ & 140 & 600 & 0.5 & 4.0 \\
\hline Галоперидол & $\mathrm{C}_{21} \mathrm{H}_{23} \mathrm{ClFNO}_{2}$ & 375 & $152[16]$ & 160 & 140 & 2.7 & 3.5 \\
\hline \multicolumn{8}{|c|}{ Пестициды } \\
\hline Прометрин & $\mathrm{C}_{10} \mathrm{H}_{19} \mathrm{~N}_{5} \mathrm{~S}$ & 241 & $118[16]$ & 100 & 72 & 0.5 & 2.0 \\
\hline Атразин & $\mathrm{C}_{8} \mathrm{H}_{14} \mathrm{~N}_{5} \mathrm{Cl}$ & 215 & $175[16]$ & 120 & 35 & 1.5 & 3.0 \\
\hline Трифлуралин & $\mathrm{C}_{13} \mathrm{H}_{16} \mathrm{~N}_{3} \mathrm{~F}_{3} \mathrm{O}_{4}$ & 335 & $49[16]$ & 95 & 2.5 & 6.0 & 2.5 \\
\hline Паракват & $\mathrm{C}_{12} \mathrm{H}_{14} \mathrm{~N}_{2}$ & 186 & $180[19]$ & 155 & 1.5 & 10.0 & 3.0 \\
\hline Дикват & $\mathrm{C}_{12} \mathrm{H}_{12} \mathrm{~N}_{2}$ & 184 & 335 [19] & 170 & 0.7 & 14.0 & 2.7 \\
\hline
\end{tabular}

*Температура кипения вещества.

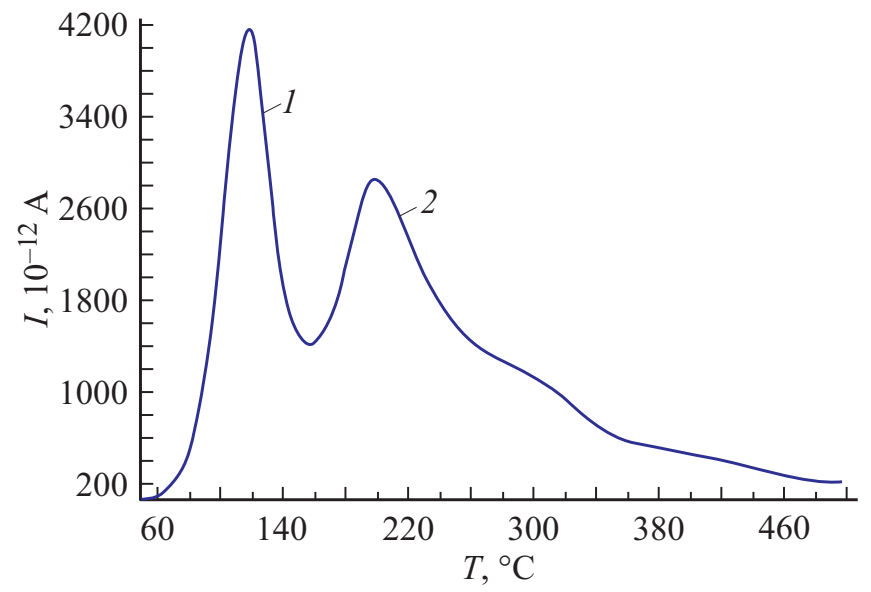

Рис. 3. ТД-спектр смеси амитриптилина и морфина. 1 - амитриптилин $(25 \mathrm{ng}), 2$ - морфин $(200 \mathrm{ng})$.

ператур сублимации. В исследованиях смесей АОС установлена аддитивность тока ТД-спектров ее компонентов. Поскольку при ПИ приходится работать при малых степенях покрытия поверхности эмиттера $(\theta \sim 0.001)$, все виды гетерогенных реакций и их скорости зависят в основном только от каталитической активности термоэмиттера и его температуры. Поэтому гетерогенные реакции ассоциации между молекулами компонентов в таких условиях маловероятны [4], и площадь под ТД-спектром смеси равна сумме площадей спектров эталонных образцов каждого вещества, взятых в отдельности и соответствующих одинаковым количествам. Это дает возможность проведения количественного анализа смесей без хроматографического разделения.

В таблице приведены данные, полученные при ТД-исследованиях: температуры испарения $T_{\max }^{s}$ (сублимации), ионизационные эффективности, определенные по площади под спектром, пределы обнаружения и линейнодинамический диапазон ряда представителей некоторых актуальных классов АОС для данной геометрии ПИД при регистрации тока термодесорбционных спектров в режиме работы над уровнем фона.

Как видно из таблицы, из исследованных 16 веществ в термодесорбционных спектрах температурные максимумы для девяти веществ являются сублимационными, для четырех веществ имеет место испарение из жидкого состояния, для трех веществ отсутствуют данные о температурах плавления $T_{m}$. Как известно, процесс сублимации - это переход вещества из твердого состояния сразу в газообразное, минуя стадию плавления. Эффективность ионизации изменяется от вещества к веществу и увеличивается от диквата $(1 \mathrm{C} / \mathrm{mol})$ к амитриптилину $(900 \mathrm{C} / \mathrm{mol})$. Пределы обнаружения АОС, определенные по калибровочным кривым, составляют от 0.1 до 14.0 pmol. Линейно-динамический диапазон, который определялся по соотношению $m_{\max } / m_{\min }$ (где $m_{\max }$ и $m_{\min }$ - соответственно максимальное и минимальное значения вводимого вещества, при которых начинается отклонение от линейности выходного сигнала), для 
исследованных веществ составил от 2.0 до 4.5 порядков величин. Такая большая разница в термодесорбционных и поверхностно-ионизационных характеристиках АОС находится в согласии с эффективностью ионизации, установленной путем ПИ азотистых оснований $[12,13]$ и терпеновых углеводородов [6].

Разработанный метод и ТД-спектрометр, несмотря на свою простоту, позволяют осуществить экспрессное ( $3 \mathrm{~min}$ на одно измерение) получение информации о термодесорбционных и поверхностно-ионизационных характеристиках АОС и обнаружение их следовых количеств с высокой чувствительностью в экстрактах биорастворов, криминалистических материалов и продуктов питания.

\section{Финансирование работы}

Работа выполнена в рамках проекта ФА-Атех-2018-17 Министерства инновационного развития Республики Узбекистан.

\section{Конфликт интересов}

Авторы заявляют, что у них нет конфликта интересов.

\section{Список литературы}

[1] Темердашев А.З., Григорьев А.М., Рыбальченко И.В. // Журн. аналит. химии. 2016. Т. 71. № 1. С. 3-22.

[2] Проблемы аналитической химии. Т. 13. Внелабораторный химический анализ / Под ред. Ю.А. Золотова. М.: Наука, 2010. $563 \mathrm{c}$.

[3] Капустин В.И., Коржсавый А.П. // Рос. технол. журн. 2016. T. 4. № 2. C. 3-24.

[4] Rasulev U.Kh., Zandberg E.Ya. // Prog. Surf. Sci. 1988. V. 28. N 3/4. P. 181-412.

[5] Rasulev U.Kh., Khasanov U., Palitcin V.V. // J. Chromatogr. A. 2000. V. 896. P. 3-18.

[6] Fujii T. // Eur. Mass. Spectrom. 1996. V. 2. P. 91-114.

[7] Ishii A., Watanabe-Suzuki K., Seno H., Suzuki O., Katsumata Y. // J. Chromatogr. B. 2002. V. 776. P. 3-14.

[8] Wu Ch., Hill H.H., Rasulev U.Kh., Nazarov E.G. // Anal. Chem. 1999. V. 71. P. 273-278.

[9] Буряков И.А., Крылов Е.В., Макась А.Л., Назаров Э.Г., Первухин В.В., Расулев У.Х. // Письма в ЖТФ. 1991. Т. 17. B. 12 . C. $60-65$.

[10] Исхакова С.С., Михайлин А.В., Расулев У.Х., Сагатов Я.Р., Хасанов У. // Журн. аналит. химии. 2004. Т. 59. № 1. C. 58-63.

[11] Rasulev U.K., Iskhakova S.S., Khasanov U., Mikhalin A.V. // Int. J. Ion Mob. Spectrom. 2001. V. 4. P. 212-225.

[12] АФанасьева Е.Ю. // ФТТ. 2014. Т. 56. В. 8. С. 1588-1592.

[13] Нагорнов К.О., Капустин В.И., Буи А.А., Каменцев К.Е. // Перспективные материалы. 2010. № 1. С. 33-40.

[14] Капустин Д.В., Буи А.А., Нагорнов К.О., Капустин В.И. // Письма в ЖТФ. 2012. Т. 38. В. 4. С. 83-88.

[15] Расулев У.Х., Назаров Э.Г., Петушков Е.Е., Стамов А.А., Козлов Ю.П. // Высокочистые вещества. 1993. № 2. C. $127-130$.
[16] Кипер P.A. Свойства веществ. Справочник по химии. Хабаровск, 2013. $1016 \mathrm{c}$.

[17] https://ru.qwe.wiki/wiki/amphetamine

[18] http://www.chemspider.com

[19] https://ru.wikipedia.org/wiki/paraquat 